\title{
Sono-Photo Fenton Treatment of Liquid Waste Containing Ethylenediaminetetraacetic Acid (EDTA)
}

\author{
S. Chitra ${ }^{1 *}$, K. Paramasivan ${ }^{1}$, P. K. Sinha ${ }^{2}$ \\ ${ }^{1}$ Centralised Waste Management Facility, Bhabha Atomic Research Centre Facilities, Kalpakkam, India \\ ${ }^{2}$ Waste Management Division, Bhabha Atomic Research Centre (BARC), Mumbai, India \\ Email: "schitra@igcar.gov.in
}

Received November 30, 2012; revised December 31, 2012; accepted January 10, 2013

Copyright (C) 2013 S. Chitra et al. This is an open access article distributed under the Creative Commons Attribution License, which permits unrestricted use, distribution, and reproduction in any medium, provided the original work is properly cited.

\begin{abstract}
Ethylenediaminetetraacetic acid (EDTA) is a chelating agent that has been used for decontamination purposes in nuclear industry. The presence of EDTA in decontamination wastes can cause complexation of the cations resulting into interferences in their removal by various treatment processes such as chemical precipitation, ion exchange etc. Further, it might also impart elevated leachability of cationic contaminants from the conditioned wastes immobilized in cement or other matrices and can negatively influence the quality of the final form of waste. In the present study, kinetics of degradation of EDTA $(20,000 \mathrm{mg} / \mathrm{l})$ by employing either Photo-Fenton process using UV $\left(15 \mathrm{~W} \lambda_{\max }=253.7 \mathrm{~nm}\right)$ or Sono-Fenton process using ultrasound at $130 \mathrm{KHz}$ or simultaneous Sono-Photo Fenton process has been investigated. EDTA is effectively degraded by the synergistic effect of both Photo Fenton and Sono Fenton process. All the above mentioned processes were found to follow a first order kinetics reaction. From the observed $\mathrm{pH}$ changes during the oxidation processes, it can be concluded that there is a loss of chelating ability of EDTA. Formation of amides was confirmed during the degradation processes.
\end{abstract}

Keywords: Advanced Oxidation Process (AOP); EDTA; Fenton’s Reagent; Sono-Photofenton

\section{Introduction}

Ethyelenediaminetetraacetic acid (EDTA) has numerous applications, based on its ability to control the action of different metal ions through complexation. EDTA is one of the most important components found in bath used for electroless plating, metal etching, surface cleaning, selective removal of precious metals from waste water emerging from non ferrous metallurgical extraction processes [1-3]. The influence of EDTA as crystal habit modifier an important stage of the Bayer process for production of alumina from bauxite ore is worth mentioning [4]. EDTA is used as an important decontaminating agent in nuclear industry. The presence of EDTA in decontamination wastes can cause complexation of the cations resulting into interferences in their removal by various treatment processes such as chemical precipitation, ion exchange etc. [5]. Further, it might also impart elevated leachability and higher mobility of cationic contaminants from the conditioned wastes i.e. waste immobilized in cement or other matrices and can negatively influence the quality of the final form of waste [6]. EDTA is not

${ }^{*}$ Corresponding author. easily biodegradable [7], scarcely degradable by chlorine [8] and hardly retained by activated carbon filters [9].

As a consequence, techniques suitable for destruction of EDTA are needed to render the liquid waste amenable to treatment and thus protect the environment. In light of the increasing concern over the contamination of the environment by hazardous chemicals, there is a great need to develop innovative technologies for the safe destruction of toxic pollutants. The processes must be cost effective, easy to operate, and capable of achieving a total or near-total mineralization.

Advanced Oxidation Processes (AOP) involving hydroxyl radicals, which are one of the strongest inorganic oxidants next to elemental fluorine, have been extremely effective in the destruction of organic pollutants. These advanced chemical oxidation process (AOP) generally use a combination of oxidation agents (such as $\mathrm{H}_{2} \mathrm{O}_{2}$ or $\mathrm{O}_{3}$ ), irradiation (such as UV or ultrasound), and catalysts (such as metal ions or photo catalysts), as a means to generate hydroxyl radicals [10]. The reason that $\mathrm{H}_{2} \mathrm{O}_{2}$ can be used for such diverse applications is the different ways in which its selectivity can function. $\mathrm{H}_{2} \mathrm{O}_{2}$ has none of the problems of gaseous release or chemical residues 
that are associated with other chemical oxidants. By simply adjusting the conditions of the reaction (e.g., $\mathrm{pH}$, temperature, dose, reaction time, and/or catalyst addition), $\mathrm{H}_{2} \mathrm{O}_{2}$ can often be made to oxidize one pollutant over another, or even to favor different oxidation products from the same pollutant.

The degradation of EDTA has been attempted by ozonation [11], $\mathrm{UV}+\mathrm{H}_{2} \mathrm{O}_{2}$ [12], phototcatalysis [5], UV + oxidants [13], radiolysis [14], radio-photocatalysis [15] and combined techniques [16] with variable results. Degradation of EDTA using $\mathrm{H}_{2} \mathrm{O}_{2}$ alone at alkaline $\mathrm{pH}$ has also been reported [17].

The treatment of liquid waste generated during the chemical decontamination of heat exchangers of the boilers of the Pressurised Heavy Water Reactor (PHWR) was planned to be taken up at Centralised Waste Management Facility (CWMF), Kalpakkam, using Advanced Oxidation Processes. The decontamination wastes contain EDTA (2\%), Ethylenediamine (EDA) (0.6\%), Ammonia $(0.6 \%)$ and hydrazine $(0.1 \%)$.

For the optimization of the waste treatment conditions, information on the influence of the experimental conditions on the degradation is needed. Since the concentration of EDTA is the maximum $(20,000 \mathrm{mg} / \mathrm{L})$, a systematic study of the degradation of $20,000 \mathrm{mg} / \mathrm{L}$ of EDTA alone using advanced oxidation processes was attempted initially. In the present study, without taking into consideration the formation of degradation intermediates, a comparison of kinetics of degradation of $20,000 \mathrm{mg} / \mathrm{L}$ of EDTA was carried out using stoichiometric quantities of $\mathrm{H}_{2} \mathrm{O}_{2}(30 \% \mathrm{w} / \mathrm{v})$ in all the experiments viz., using UV $(15 \mathrm{~W})+$ Fenton's reagent $\left(\mathrm{FeII}+\mathrm{H}_{2} \mathrm{O}_{2}\right)$, US $(130 \mathrm{KHz})$ $+\mathrm{FeII}+\mathrm{H}_{2} \mathrm{O}_{2}$, and UV $(15 \mathrm{~W})+\mathrm{US}(130 \mathrm{KHz})+\mathrm{FeII}+$ $\mathrm{H}_{2} \mathrm{O}_{2}$ was carried out at $\mathrm{pH} 3.0$.

\section{Experimental}

\subsection{Experimental Setup and Materials}

The photoreactor was a glass trough (Borosil) with inside dimensions of $210 \times 210 \times 50 \mathrm{~mm}$ deep. A UV lamp (8 W with $\lambda_{\max }=253.7 \mathrm{~nm}$ ) was positioned horizontally over the reactor. The distance of the UV lamp from the surface of the sample was maintained at $70 \mathrm{~mm}$. The set-up was housed inside a fume hood. For the experiments carried out using UV lamp ( $8 \mathrm{~W})$, an aluminum cover was used to house the glass trough to control the UV radiation. The light intensity inside the reacting medium as determined by potassium ferrioxalate actinometry was $3.5 \mathrm{E}-3$ einsteins $/ \mathrm{cm}^{2}$. The schematic diagram of the experimental set-up used in the study is shown in Figure 1.

Sonication experiments were performed in an ultrasonic cleaning bath of frequency $130 \mathrm{KHz}$ ELMA Transonic industrial table top model T1-H-20-MF of power

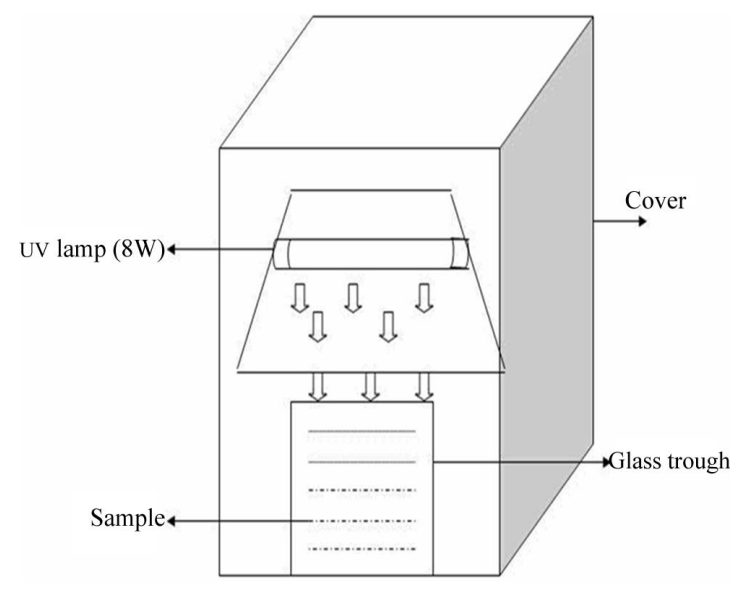

Figure 1. Experimental setup.

$300 \mathrm{~W}$. The reactions were carried out using a similar glass trough (Borosil) as used for Photo Fenton experiment with inside dimensions of $210 \times 210 \times 50 \mathrm{~mm}$ deep which was closed during ultrasonic irradiation. The glass trough was placed inside the ultrasonic bath. In addition to the above-mentioned instrumentation, a standard $\mathrm{pH}$ meter was used. The $\mathrm{pH}$ value of the solution was adjusted using $\mathrm{H}_{2} \mathrm{SO}_{4}$ solution.

For Sono-Photo Fenton experiments the photoreactor was placed inside the ultrasonic cleaning bath of frequency $130 \mathrm{KHz}$ ELMA Transonic industrial table top model T1-H-20-MF of power $300 \mathrm{~W}$.

All the chemicals EDTA disodium salt, hydrogen peroxide $(30 \%), \mathrm{FeSO}_{4}, \mathrm{MgSO}_{4} \cdot 7 \mathrm{H}_{2} \mathrm{O}$ was of analytical grade, $99.9 \%$ purity.

\subsection{Degradation Procedures}

By stoichiometric calculations, 17 moles of $\mathrm{H}_{2} \mathrm{O}_{2}$ are required to completely oxidize $1 \mathrm{~mol}$ of EDTA to $\mathrm{CO}_{2}$, $\mathrm{NH}_{3}$ and $\mathrm{H}_{2} \mathrm{O}$. The balanced stoichiometric Equation (1) is as follows:

$$
\begin{aligned}
& \mathrm{C}_{10} \mathrm{H}_{14} \mathrm{~N}_{2} \mathrm{Na}_{2} \mathrm{O}_{8} 2 \mathrm{H}_{2} \mathrm{O}+17 \mathrm{H}_{2} \mathrm{O}_{2} \\
& \rightarrow 10 \mathrm{CO}_{2}+2 \mathrm{NH}_{3}+22 \mathrm{H}_{2} \mathrm{O}+2 \mathrm{NaOH}
\end{aligned}
$$

To $898 \mathrm{ml}$ of 22,500 mg/L EDTA solution taken in the photoreactor, $0.002 \%(\mathrm{w} / \mathrm{v})$ of $\mathrm{Fe}^{2+}$ was added and mixed thoroughly before the addition of $102 \mathrm{ml} \mathrm{H}_{2} \mathrm{O}_{2}(30 \%$ $\mathrm{w} / \mathrm{v})$. The amount of $\mathrm{Fe}^{2+}$ added was arrived at by considering the maximum concentration of interference of $\mathrm{Fe}^{2+}$ that may be present in the sample and still permit the titration with EDTA [18]. The time at which the UV lamp/US system was turned on was considered time zero or the beginning of the experiment.

\subsection{Analytical Methods}

The $\mathrm{pH}$ of the solution was measured using a calibrated pocket $\mathrm{pH}$ meter $(\mathrm{HACH})$ at appropriate time intervals 
and during those time intervals $5 \mathrm{ml}$ of the sample was pipetted into a conical flask. One drop of hydrazine was also added to prevent $\mathrm{H}_{2} \mathrm{O}_{2}$ from reacting with organic substrates during the analysis. The residual EDTA present in the samples was analysed titrimetrically against standard $\mathrm{Mg}^{2+}$ using Eriochrome Black $\mathrm{T}$ as indicator [19]. The hydrogen peroxide was measured by the standard iodometric titration [20]. At least triplicate runs were carried out for each condition averaging the results.

\section{Results and Discussion}

\subsection{Comparison of UV/Fenton, US/Fenton and US-UV/Fenton}

Figure 2 illustrates the comparison of percent degradation of EDTA $(20,000 \mathrm{mg} / \mathrm{L})$ as a function of time using $\mathrm{UV}+\mathrm{Fe}(\mathrm{II})+\mathrm{H}_{2} \mathrm{O}_{2}$, US $+\mathrm{Fe}(\mathrm{II})+\mathrm{H}_{2} \mathrm{O}_{2}$ and $\mathrm{US}+\mathrm{UV}+$ $\mathrm{Fe}(\mathrm{II})+\mathrm{H}_{2} \mathrm{O}_{2}$. From Figure 2 it can be observed that there was complete degradation of EDTA at 20 hours, 10 hours and 5 hours for samples treated with US (130 KHz) $+\mathrm{Fe}(\mathrm{II})+\mathrm{H}_{2} \mathrm{O}_{2}, \mathrm{UV}(15 \mathrm{~W})+\mathrm{Fe}(\mathrm{II})+\mathrm{H}_{2} \mathrm{O}_{2}$, US $+\mathrm{UV}+$ $\mathrm{Fe}(\mathrm{II})+\mathrm{H}_{2} \mathrm{O}_{2}$ respectively.

The rate of degradation by $\mathrm{UV}(8 \mathrm{~W})+$ FeII $+\mathrm{H}_{2} \mathrm{O}_{2}$ was 2.3 times faster than that in the system using US $(130 \mathrm{KHz})+$ FeII $+\mathrm{H}_{2} \mathrm{O}_{2}$. The formation of hydroxyl radicals by using the photo-Fenton process occurs according to the following Equation (2) [10]

$$
\mathrm{Fe}^{2+}+\mathrm{H}_{2} \mathrm{O}_{2} \rightarrow \mathrm{Fe}^{3+}+\mathrm{OH}^{-}+\mathrm{OH}^{\bullet}
$$

Equation (2), known as the Fenton reaction, possesses a high oxidation potential, but its application to wastewater treatment began only recently [21].

In combination of thermal process and UV irradiation, the oxidation power of Fenton's reagent was significantly increased mainly due to photo-reduction of $\mathrm{Fe}^{3+}$ to $\mathrm{Fe}^{2+}$, which could react with $\mathrm{H}_{2} \mathrm{O}_{2}$ establishing a cycle mechanism of generating additional hydroxyl radicals which is

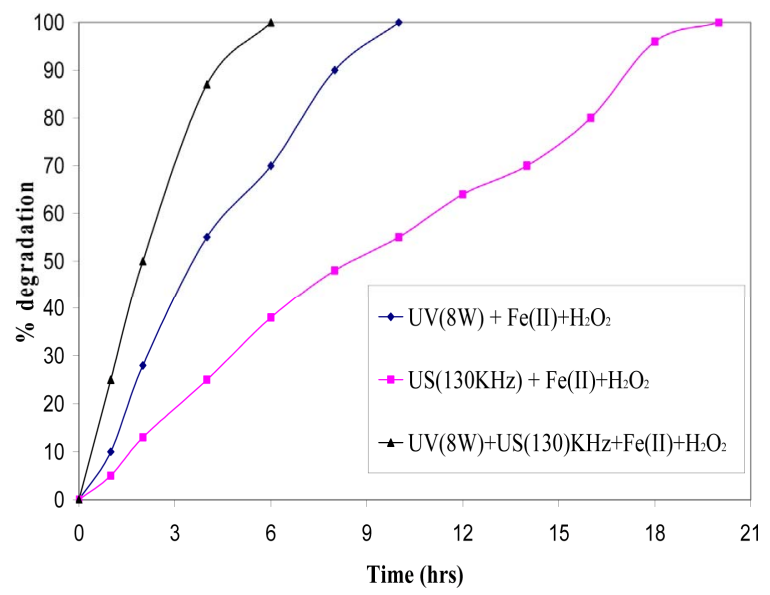

Figure 2. Comparison of advanced oxidation processes for degradation of EDTA (2\%). shown by Equation (3) [22].

$$
\mathrm{Fe}^{3+}+\mathrm{H}_{2} \mathrm{O}_{2}+h v \rightarrow * \mathrm{OH}+\mathrm{Fe}^{2+}+\mathrm{H}^{+}
$$

The temperature of the reaction process was found to vary from $28^{\circ} \mathrm{C}-32^{\circ} \mathrm{C}$. Furthermore, the effect of UV light also attributed to the direct hydroxyl radical formation and regeneration of $\mathrm{Fe}^{2+}$ from the photolysis of the complex $\mathrm{Fe}(\mathrm{OH})^{2+}$ in solution Equation (4).

$$
\mathrm{Fe}(\mathrm{OH})^{2+}+h v \rightarrow * \mathrm{OH}+\mathrm{Fe}^{2+}
$$

From the simultaneous application of UV and Fenton's reagent there is considerable synergistic effect on the rate of degradation of EDTA.

Irradiation by high power ultrasound in a liquid leads to the acoustic cavitations phenomenon, such as the formation, growth and collapse of bubbles, accompanied by the generation of local high temperature, pressure and reactive radical species. This conditions lead to some chemical reactions in three phases: internal cavity, interface boundary layer and the bulk liquid Thermal decomposition may take place in the internal parts of the cavities. The reactions with radicals occur in the interface boundary layer. In wastewater treatment a bubble of cavitation may function as a micro-reactor inside which, the volatile compounds are destroyed. During sonolysis of water and in the presence of oxygen, the cavity may also be considered as source of $\mathrm{H}^{\bullet},{ }^{\bullet} \mathrm{OH}, \mathrm{HOO}^{\bullet}$ radicals, which have been extremely effective in the destruction of organic pollutants [22].

To enhance the efficiency of degradation, a more effective utilization of $\mathrm{OH}$ radicals is desirable. It is expected that addition of $\mathrm{Fe}(\mathrm{II})+\mathrm{H}_{2} \mathrm{O}_{2}$ will regenerate ${ }^{\circ} \mathrm{OH}$, thus accelerating the rate of degradation and thereby increasing the efficiency of ultrasonic degradation [23].

In spite of the fact that irradiation of a treatment medium using ultrasound in combination with Fenton's reagent also lead to formation of free radicals similar to a Photo Fenton process the kinetics of degradation of EDTA in the Sono Fenton process is slow compared to Photo Fenton process. In the case of photochemical degradation there was direct exposure of UV radiation onto the reaction medium whereas in the case of sonodegradation there could have been attenuation of the sound wave by the glass medium due to the placement of the glass trough inside the ultrasonic bath. Due to the above, the number of cavitation bubbles produced in the reaction vessel may be less. The decomposition rate is dependent on the rate of formation of ${ }^{\bullet} \mathrm{OH}$ that is the rate of cavitation occurrence, which is a function of cavitation period and number of transient cavitation bubbles and also on the concentration of the pollutant [24]. The factors viz., the operating conditions (frequency and power dissipation per unit volume) and the equipment configuration decide the rate of generation of free radicals due to the ultrasonic action. Sono-Fenton degradation process is 
very much dependent on the utilization of free radicals by the pollutant molecules, which in turn is dependent on the efficiency of contact of the generated free radicals with the pollutant over a specified time period [25]. The kinetics of the Sono-Fenton process for degradation of EDTA $(20,000 \mathrm{mg} / \mathrm{l})$ can be accelerated by the use of a higher frequency and higher power of ultrasound or by usage of a horn type sonicator for direct production and interaction of hydroxyl free radicals with the pollutant. The above observation is also in conformity with literature where it has been cited that multiple frequency reactors have been found to generate more intense and spatially uniform cavitation as compared to reactors with single frequency and/or single transducer operation [26] and hence these give better destruction efficiency [27].

The time taken for EDTA degradation due to the integral effect of both US $(130 \mathrm{KHz})+\mathrm{UV}(8 \mathrm{~W})+\mathrm{Fe}(\mathrm{II})+$ $\mathrm{H}_{2} \mathrm{O}_{2}$ was found to be at 5 hours which is twice and four times lesser than application of UV/Fenton and US/ Fenton respectively. The expected synergism between different hybrid methods discussed in the present work is mainly due to an identical controlling reaction mechanism, i.e. the free radical attack. Generally, combination of two or more advanced oxidation processes, sono-photochemical/sono-photocatalytic oxidation etc. leads to an enhanced generation of the hydroxyl radicals, which eventually results in higher oxidation rates. The efficacy of the process and the extent of synergism depend not only on the enhancement in the number of free radicals but also on the alteration of the reactor conditions or configuration leading to a better contact of the generated free radicals with the pollutant molecules and also better utilization of the oxidants and catalytic activity [26]. The synergistic process may lead to complete mineralization by oxidizing the organic intermediates.

In all the UV/US/US + UV Fenton processes there was a change in $\mathrm{pH}$ from 3.0 to 8.5 as the reaction proceeded. From the above, it can be inferred that there was loss of acidity and hence the loss of chelating ability of EDTA [13]. This was confirmed titrimetrically. Since there was a change in $\mathrm{pH}$ from acidic range to alkaline range as the reaction proceeded, formation of acidic intermediates is ruled out and formation of either amines or amides was suspected. The qualitative hydroxamic acid test was positive wherein a deep red colored solution was obtained on treatment with hydroxylamine and ferric chloride and thus formation of amides was confirmed. The above observation is in agreement with the results obtained for the mechanistic formation of intermediates in UV/US + Fenton processes [21].

\subsection{Kinetics of Degradation of EDTA by UV/US/UV + US-Fenton Processes}

The rate of degradation of EDTA was investigated for the systems UV $+\mathrm{US}+$ FeII $+\mathrm{H}_{2} \mathrm{O}_{2}$, US $(130 \mathrm{KHz})+$
FeII $+\mathrm{H}_{2} \mathrm{O}_{2}$ and $\mathrm{UV}(8 \mathrm{~W})+\mathrm{FeII}+\mathrm{H}_{2} \mathrm{O}_{2}$. The degradation of EDTA was observed as a function of time and the data were fitted to a first-order rate model as shown in Equation (5)

$$
\ln C_{1} / C_{0}=-k_{0} t
$$

where $\mathrm{C}_{0}$ and $\mathrm{C}_{t}$ are the concentration of EDTA at times 0 , and $t, k_{0}$ is a first order rate constant $\left(\mathrm{hr}^{-1}\right)$ and $t$ is the time (hrs). The rate constants were determined using a first order rate model [Equation (5)]. The results are listed in Table 1. From the data in Table 1, it can be observed that the rate of EDTA degradation due to the integral effect of both US $(130 \mathrm{KHz})+\mathrm{UV}(8 \mathrm{~W})+\mathrm{Fe}(\mathrm{II})+$ $\mathrm{H}_{2} \mathrm{O}_{2}$ is found to be 1.7 and 3.8 times greater than application of UV/Fenton and US/Fenton respectively. Hence, rate of degradation follows the order $\mathrm{UV}+\mathrm{US}+\mathrm{FeII}+$ $\mathrm{H}_{2} \mathrm{O}_{2}>\mathrm{UV}(8 \mathrm{~W})+\mathrm{FeII}+\mathrm{H}_{2} \mathrm{O}_{2}>\mathrm{US}(130 \mathrm{KHz})+\mathrm{FeII}$ $+\mathrm{H}_{2} \mathrm{O}_{2}$.

The ratio of the Sono-Photo-Fenton rate constant to the sum of the rate constants of the individual processes was used to evaluate the synergistic effect of the combined system as shown in Equation (6)

$$
\text { Synergistic Index }=k_{\text {sonophoto }} /\left[k_{\text {sono }}+k_{\text {photo }}\right]
$$

where $k_{\text {sonophoto, }} k_{\text {sono }}$ and $k_{\text {photo }}$ are the rate constants for Sono-Photo Fenton, Sono-Fenton and Photo-Fenton process respectively [28]. The synergistic index was found to be 1.16 for the Sono-Photo-Fenton degradation of EDTA $(20,000 \mathrm{mg} / \mathrm{l})$. The rate constant for the Sono-Photo Fenton process was found to be additive of the rate constants of the Sono-Fenton and photo-Fenton process as shown in Table 1.

\section{Conclusion}

The results from the comparative study on the kinetics of EDTA degradation revealed that the reaction using UV + $\mathrm{US}+\mathrm{FeII}+\mathrm{H}_{2} \mathrm{O}_{2}$ was faster than that obtained in any of the other processes viz., UV $(8 \mathrm{~W})+$ FeII $+\mathrm{H}_{2} \mathrm{O}_{2}$, US $(130 \mathrm{KHz})+\mathrm{FeII}+\mathrm{H}_{2} \mathrm{O}_{2}$ respectively. Sono-Photo Fenton process effectively degrades the EDTA. The synergistic effect is attributable to effective enhancement of Photo-Fenton oxidation by Sono-Fenton oxidation. From the observed $\mathrm{pH}$ changes during either Photo-Fenton or

Table 1. Reaction rate constants for the degradation of EDTA (2\%) using.

\begin{tabular}{ccc}
\hline Types of oxidation process & $\mathrm{K}_{0}\left(\mathrm{hr}^{-1}\right)$ & $\mathrm{R}^{2}$ \\
\hline $\begin{array}{c}\mathrm{UV}(8 \mathrm{~W})+\mathrm{US} \\
(130 \mathrm{kHz})+\mathrm{Fe}(\mathrm{II})+\mathrm{H}_{2} \mathrm{O}_{2}\end{array}$ & $0.5 \pm 0.02$ & 0.97 \\
$\mathrm{UV}(8 \mathrm{~W})+\mathrm{Fe}(\mathrm{II})+\mathrm{H}_{2} \mathrm{O}_{2}$ & $0.3 \pm 0.01$ & 0.96 \\
$\mathrm{US}(130 \mathrm{kHz})+\mathrm{Fe}(\mathrm{II})+\mathrm{H}_{2} \mathrm{O}_{2}$ & $0.13 \pm 0.03$ & 0.99 \\
\hline
\end{tabular}


Sono-Fenton or Sono-Photo Fenton processes, it can be concluded that there is a loss of chelating ability of EDTA and formation of amides was confirmed.

\section{REFERENCES}

[1] Q.-H. Tian and X.-Y. Guo, "Electroless Copper Plating on Microcellular Polyurethane Foam," Transactions of Nonferrous Metals Society of China, Vol. 20, Suppl. 1, 2010, pp. s283-s287. doi:10.1016/S1003-6326(10)60057-X

[2] P. Pitter and V. Sykora, "Biodegradability of Ethylene Diamine-Based Complexing Agents and Related Compounds," Chemosphere, Vol. 44, No. 4, 2001, pp. 823826. doi:10.1016/S0045-6535(00)00512-9

[3] D. Li, X. Wu, D. Wang and J. A. Finch, "Selective Removal of Nickel from Iron Substrate by Non-Cyanide Stripper," Transactions of Nonferrous Metals Society of China, Vol. 14, No. 3, pp. 599-602.

[4] B.-L. Lu, Q.-Y. Chen, Z.-L. Yin and H.-P. Hu, "Effects of Na4EDTA and EDTA on Seeded Precipitation of Sodium Aluminate Solution," Transactions of Nonferrous Metals Society of China, Vol. 20, No. z1, 2010, pp. s37-s41.

[5] S. Chitra, S. Chandran, P. Sasidhar, K. B. Lal and R. V. Amalraj, "Biodegradation of Surfactant Bearing Wastes," Indian Journal of Environmental Protection, Vol. 11, No. 9,1991, pp. 689-692.

[6] K. Rosikova, J. John, E. Danacikova-Popelova, F. Sebesta and E. W. Hooper, "Study of EDTA Photodegradation," Proceedings of 4th Institute for International Cooperative Environmental Research, Florida State University, Tallahassee, 1998, pp. 379-385.

[7] M. L. Hinck, J. Ferguson and J. Puhaakka, "Resistance of EDTA and DTPA to Aerobic Biodegradation," Water Science and Technology, Vol. 35, No. 2-3, 1997, pp. 2531. doi:10.1016/S0273-1223(96)00911-0

[8] H. J. Brauch and S. V. Schullerer, "EDTA and NTA Beider Trinkwasseraufbereitung," Vom Wasser, Vol. 69, 1987, pp. 155-164.

[9] S. V. Schullerer and H. J. Brauch, "Oxidative and Adsorptive Behandlung EDTA and NTA Haltiger Wasser," Vom Wasser, Vol. 72, 1989, pp. 23-29.

[10] C. P. Huang, D. Cheng and Z. H. Tang, "Advanced Chemical Oxidation: Its Present Role and Potential Future in Hazardous Waste Treatment," Waste Management, Vol. 13, No. 5-7, 1993, pp. 361-377. doi:10.1016/0956-053X(93)90070-D

[11] E. Gilbert and S. Hoffmann-Glewe, "Ozonation EDTA in Aqueous Solution, Influence of $\mathrm{pH}$ Value and Metal Ions," Water Research, Vol. 24, No. 1, 1990, pp. 39-44. doi:10.1016/0043-1354(90)90062-B

[12] M. Sorensen and F. H. Frimmel, "Photodegradation of EDTA and NTA in the UV/ $\mathrm{H}_{2} \mathrm{O}_{2}$ Process," Zeitschrift für Naturforschung, Vol. 50, No. 12, 1995, pp. 1845-1853.

[13] M. D. Tucker, L. L. Barton, B. M. Thomson, B. M. Wagener and A. Aragon, "Treatment of Waste Containing EDTA by Chemical Oxidation," Waste Management, Vol. 19, No. 7-8, 1999, pp. 477-482.

\section{doi:10.1016/S0956-053X(99)00235-4}

[14] K. Krapfenbauer and N. Getoff, "Comparative Studies of Photo-and-Radiation-Induced Degradation of Aqueous EDTA. Synergistic Effects of Oxygen, Ozone and $\mathrm{TiO}_{2}$," Radiation Physics and Chemistry, Vol. 55, No. 4, 1999, pp. 385-393. doi:10.1016/S0969-806X(99)00205-4

[15] Y. Su, Y. Wang, J. L. Daschbach, T. B. Fryberger, M. A. Henderson, J. Janata and C. H. F. Peden, "Gamma Ray Destruction of EDTA Catalyzed by Titania," Journal of Advanced Oxidation Technology, Vol. 3, 1998, pp. 63-69.

[16] S. Kagaya, Y, Bitoh and K. Hasegawa, "Photocatalyzed Degradation of Metal-EDTA Complexes in $\mathrm{TiO}_{2}$ Aqueous Suspensions and Simultaneous Metal Removal," Chemical Letters, Vol. 26, No. 2, 1997, pp. 155-156. doi:10.1246/cl.1997.155

[17] J. Ramo and M. Sillanpaa, "Degradation of EDTA by Hydrogen Peroxide in Alkaline Conditions," Journal of Cleaner Production, Vol. 9, No. 3, 2001, pp. 191-195. doi:10.1016/S0959-6526(00)00049-4

[18] American Public Health Association, "Standard Methods for the Examination of Water and Wastewater," New York, 1975.

[19] A. I. Vogel, "Quantitatative Inorganic Analysis," 3rd Edition, Longman Publishing, London, 1939.

[20] M. Y. Ghaly, H. Georg, M. Roland and R. Haseneder, "Photochemical Oxidation of $p$-Chlorophenol by $\mathrm{UV} / \mathrm{H}_{2} \mathrm{O}_{2}$ and Photo-Fenton Process. A Comparative Study," Waste Management, Vol. 21, No. 1, 2001, pp. 41-47. doi:10.1016/S0956-053X(00)00070-2

[21] P. A. Babay, D. A. Batistoni, D. A. Ferreyra, E. A. Gautier, R. T. Gettar and M. I. Litter, "Kinetics and Mechanisms of EDTA Photocatalytic Degradation with $\mathrm{TiO}_{2}$," Water Science and Technology, Vol. 44, No. 5, 2001, pp. 179-185.

[22] Y. G. Adewuyi, "Sonochemistry: Environmental Science and Engineering Applications," Industrial \& Engineering Chemistry Research, Vol. 40, No. 22, 2001, pp. 46814715. doi:10.1021/ie0100961

[23] B. Yim, H. Okuno, N. Nagata and Y. Maeda, "Sonolysis of Surfactants in Aqueous Solutions: An Accumulation of Solute in the Interfacial Region of the Cavitation Bubbles," Ultrasonics Sonochemistry, Vol. 9, No. 4, 2002, pp. 209-213. doi:10.1016/S1350-4177(01)00123-7

[24] Y. Suzuki, Warsito, A. Maezawa and S. Uchida, "Effects of Frequency and Aeration Rate on Ultrasonic Oxidation of a Surfactant," Chemical. Engineering Technology, Vol. 22, No. 6, 1999, pp. 507-510. doi:10.1002/(SICI)1521-4125(199906)22:6<507::AID-C EAT507>3.0.CO;2-D

[25] R. Parag Gogate and B. Aniruddha Pandit, "A Review of Imperative Technologies for Wastewater Treatment II: Hybrid Methods," Advances in Environmental Research, Vol. 8, No. 3-4, 2004, pp. 553-597. doi:10.1016/S1093-0191(03)00031-5

[26] P. A. Tatake and A. B. Pandit, "Modelling and Experimental Investigation into Cavity Dynamics and Cavitational Yield: Influence of Multiple Frequency Ultrasound Sources," Chemical Engineering Science, Vol. 57, No. 22, 2002, pp. 4987-4995. 
doi:10.1016/S0009-2509(02)00271-3

[27] M. Sivakumar, P. A. Tatake and A. B. Pandit, "Kinetics of p-Nitrophenol Degradation: Effect of Reaction Conditions and Cavitational Parameters for a Multiple Frequency System," Chemical Engineering Journal, Vol. 85, No. 2-3, 2002, pp. 327-338.

doi:10.1016/S1385-8947(01)00179-6
[28] Y. He, F. Grieser and M. Ashokkumar, "The Mechanism of Sonophotocatalytic Degradation of Methyl Orange and Its Products in Aqueous Solutions," Ultrasonics Sonochemistry, Vol. 18, No. 5, 2011, pp. 974-990. doi:10.1016/j.ultsonch.2011.03.017 